\begin{tabular}{|c|c|c|}
\hline \multirow{3}{*}{$\begin{array}{r}\text { Case Reports in } \\
\text { Gastroenterology }\end{array}$} & \multicolumn{2}{|c|}{ Case Rep Gastroenterol 2016;10:589-595 } \\
\hline & $\begin{array}{l}\text { DOI: } 10.1159 / 000450541 \\
\text { Publisned online: Uctober 18, } 2016\end{array}$ & $\begin{array}{l}\text { (C) } 2016 \text { The Author(s) } \\
\text { Published by S. Karger AG, Basel } \\
\text { www.karger.com/crg }\end{array}$ \\
\hline & $\begin{array}{l}\text { This article is licensed under the } \\
\text { International License (CC BY-NC) } \\
\text { Usage and distribution for commerc }\end{array}$ & $\begin{array}{l}\text { nons Attribution-NonCommercial } 4.0 \\
\text { ger.com/Services/OpenAccessLicense). } \\
\text { uires written permission. }\end{array}$ \\
\hline
\end{tabular}

\title{
Successful Treatment of Small Intestinal Bleeding in a Crohn's Patient with Noncirrhotic Portal Hypertension by Transjugular Portosystemic Shunt Placement and Infliximab Treatment
}

\author{
Benjamin Heimgartner $^{\mathrm{a}} \quad$ Heather Dawson $^{\mathrm{b}} \quad$ Andrea De Gottardi $^{\mathrm{c}}$ \\ Reiner Wiest ${ }^{a}$ Jan Hendrik Niess ${ }^{a, d}$ \\ ${ }^{a}$ Division of Gastroenterology, University Clinic for Visceral Surgery and Medicine, \\ University of Bern, Bern, Switzerland; ${ }^{b}$ Clinical Pathology Division, Institute of Pathology, \\ University of Bern, Bern, Switzerland; ' $D$ Division of Hepatology, University Clinic for Visceral \\ Surgery and Medicine, University of Bern, Bern, Switzerland; ${ }^{d}$ Departments of \\ Gastroenterology and Hepatology, University Hospital Basel, Basel, Switzerland
}

\section{Keywords}

Small intestinal bleeding $\cdot$ Crohn's disease $\cdot$ Portal hypertension $\cdot$ Nodular regenerative hyperplasia $\cdot$ Transjugular intrahepatic portosystemic shunt $\cdot$ Infliximab

\begin{abstract}
Small intestinal bleeding in Crohn's disease patients with noncirrhotic portal hypertension and partial portal and superior mesenteric vein thrombosis is a life-threatening event. Here, a case is reported in which treatment with azathioprine may have resulted in nodular regenerative hyperplasia, portal hypertension and portal vein thrombosis. The 56-year-old patient with Crohn's disease developed nodular regenerative hyperplasia under treatment with azathioprine. He was admitted with severe bleeding. Gastroscopy showed small esophageal varices without bleeding stigmata. Blood was detected in the terminal ileum. CT scan revealed a partial portal vein thrombosis with extension to the superior mesenteric vein, thick-
\end{abstract}


ening of the jejunal wall and splenomegaly. Because intestinal bleeding could not be controlled by conservative treatment, the thrombus was aspirated and a transjugular intrahepatic portosystemic shunt (TIPS) was placed. Switching the immunosuppressive medication to infliximab controlled Crohn's disease activity. Bleeding was stopped, hemoglobin normalized, and thrombocytopenia and bowel movements improved. In summary, small intestinal bleeding in a Crohn's patient with nodular regenerative hyperplasia, portal hypertension and portal vein thrombosis can be efficiently treated by TIPS. TIPS placement together with infliximab treatment led to the improvement of the blood panel and remission in this patient.

\section{Introduction}

Inflammatory bowel disease (IBD) often requires treatment with immunomodulatory agents, such as purines, or with biologicals, such as anti-TNF or anti $\alpha 4 \beta 7$ integrin antibodies [1]. The purine azathioprine can cause hepatitis, pancreatitis, bone marrow depression, nausea and joint pain. Nodular regenerative hyperplasia (NRH) is observed in approximately $1.25 \%$ of patients treated for 10 years with azathioprine [2, 3]. NRH can result in portal hypertension with reduced portal flow leading to portosystemic shunts as esophageal varices, hypersplenism and thrombocytopenia [4]. 30-50\% of patients with noncirrhotic portal hypertension develop portal vein thrombosis [5, 6], which further aggravates portal hypertension. Life-threatening variceal bleedings are a serious complication of portal hypertension.

Here, a patient with Crohn's disease (CD) is reported who has likely developed azathioprine-induced NRH. A life-threatening small intestinal bleeding associated with portal hypertension was successfully managed by transjugular intrahepatic portosystemic shunt (TIPS) placement. Infliximab has been introduced into the treatment of this patient to induce and maintain remission of $\mathrm{CD}$. To our knowledge, this is the first reported CD case where a small intestinal bleeding with portal hypertension and partial thrombosis was successfully managed with TIPS placement and consecutive treatment with infliximab. Treatment with infliximab seems to be safe in this situation.

\section{Case Description}

A 54-year-old Caucasian male teacher had been admitted to the emergency unit with a circulation-relevant intestinal bleeding. The patient had a 19-year history of CD with stricturing behavior that required ileocecal resection. Five years before admission the patient had been treated with azathioprine. Two years after beginning treatment with azathioprine, leucocyte and thrombocyte numbers decreased. The patient was switched from azathioprine to methotrexate to control CD and arthralgia. Although azathioprine had been stopped and methotrexate introduced, cytopenia persisted and a bone marrow aspiration showed increased megakaryopoiesis as sign of increased peripheral consumption (fig. 1a). A CT scan revealed signs of portal hypertension with splenomegaly and portosystemic shunts (fig. 1b). Esophagogastroduodenoscopy confirmed the presence of esophageal varices with cherry red spots (fig. 1c). Propranolol ( $80 \mathrm{mg} /$ day) was introduced as primary bleeding prophylaxis. Then, transjugular liver biopsy was performed. The hepatic venous pressure gradient between the liver veins and the wedged hepatic venous pressure was $7 \mathrm{~mm}$ Hg (normal 1-5 
Heimgartner et al.: Successful Treatment of Small Intestinal Bleeding in a Crohn's Patient with Noncirrhotic Portal Hypertension by TIPS and Infliximab Treatment

$\mathrm{mm} \mathrm{Hg}$ ) under therapy with propranolol. At that time, portal vein thrombosis was not present. Liver histology revealed signs of a nodular regenerative hyperplasia (fig. 1d).

At admission the patient reported that, without seeking medical advice, he had started a therapy with prednisone $(150 \mathrm{mg} /$ day $)$ in addition to his treatment with methotrexate because he suffered from abdominal pain and increased frequency of bowel movements (diarrhea with loose stools up to 10 times per day). Physical examination showed slight tenderness of the left abdomen. Laboratory results revealed a platelet count of $44 \mathrm{~g} / \mathrm{l}$ (normal value $150-450 \mathrm{~g} / \mathrm{l}$ ). Within $2 \mathrm{~h}$ after admission, hemoglobin dropped from 121 to $100 \mathrm{~g} / \mathrm{l}$ (normal value 140-170 g/l). Emergency gastroscopy showed small esophageal and fundal gastric varices without red signs or stigmata of recent hemorrhage (fig. 2a). Ileocolonoscopy demonstrated the presence of red blood in the neoterminal ileum, but the source of the bleeding could not be identified (fig. 2b). Likely, small intestinal bleeding was present in this patient. Consecutive CT angiography showed no active bleeding but demonstrated a partial thrombosis of the superior mesenterial and portal vein and a thickened proximal jejunal bowel wall (fig. 2c). Transfusion of 4 packs of $250 \mathrm{ml}$ platelets increased the platelet count to $77,000 / \mu \mathrm{l}$. The somatostatin analog octreotide was given to lower portal pressure. However, intestinal bleeding persisted requiring the transfusion of 6 packs with $275 \mathrm{ml}$ red cells. A CT abdominal angiography was repeated and again showed no active bleeding.

Since intestinal bleeding persisted, partial thrombosis of the portal and superior mesenterial vein and clinical signs of portal hypertension with splenomegaly and portosystemic shunts were present, transhepatic pressure measurement, TIPS placement and thrombus aspiration were considered. After transjugular puncture of the portal vein, an Absolute Pro $10 \mathrm{~mm} / 60 \mathrm{~mm}$ 6F 8 stent was placed with the caudal end in the portal vein. Subsequently, a Fluency Vascular Stent Graft F9 and an additional Absolute Pro 10 mm/30mm 6F 8 stent were inlaid by stent-in-stent technique for proximal extension. After TIPS placement, the thrombus was aspirated. The pressure gradient measured directly in the portal vein and right atrium was successfully lowered from 19 to $6 \mathrm{~mm} \mathrm{Hg}$ by the intervention. Intestinal bleeding stopped after TIPS placement and the patient could be discharged home.

The patient was followed up in the outpatient clinic, where he reported episodes of arthralgia and intermittent increased frequencies of bowel movements. Infliximab therapy was introduced, which led to an improvement of arthralgia and bowel movements. Regress of the esophageal varices was observed after TIPS placement. Hemoglobin normalized and thrombocytes counts doubled within 2 years (fig. 3 ).

\section{Discussion}

The presented case describes a patient with Cohn's disease who developed NRH probably as consequence of the treatment with purines. As in our patient, risk factors for the development of NRH in IBD patients are male sex, stricturing disease behavior and small bowel resection $>50 \mathrm{~cm}$ [7]. Studies that searched for alternatives to azathioprine or 6-mercaptopurine suggested that the purine 6-thioguanine has favorable short-term safety and efficacy [8]. However, approximately one third of patients treated with 6-thioguanine developed liver abnormalities as indicated by laboratory workup. More than two third of patients with abnormal liver chemistry had signs of NRH [9]. This indicates that the purine metabolite 6-thioguanine is involved in the pathogenesis of NRH.

Noncirrhotic portal hypertension and partial thrombosis of the superior mesenterial and portal vein resulted in a life-threatening small intestinal bleeding in this patient. IBD 
patients have a two- to three-fold increased risk of suffering from thrombosis, and the majority of thrombotic events occur when active disease is present [10]. In the literature there are only few reports that describe the necessity of TIPS placement for the treatment of portal hypertension in IBD patients. For example, one study described 9 patients with primary sclerosing cholangitis who underwent colectomy. The patients who received TIPS placement prior to colectomy had higher wound infection and dehiscence rates. Likely, this was more due to greater severity of cirrhosis and primary sclerosing cholangitis in this population [11]. Successful treatment of portal hypertensive stomapathy by TIPS placement has also been reported for both $\mathrm{CD}$ and ulcerative colitis $[12,13]$.

After release from the hospital, the patient reported about arthralgia and episodes of increased bowel movements. CT scans demonstrated proximal jejunal bowel thickening. Likely, activity of CD with involvement of jejunal segments was present. Together, this indicated that the patient was at an increased risk of suffering from thrombotic insults after release from the hospital. Since purines could not be given to this patient and methotrexate inefficiently controlled inflammation, therapy with biologicals was considered. A recent prospective study demonstrated that treatment with infliximab normalizes clot lysis profiles in CD [14]. Therapy with the anti-TNF antibody infliximab was hence started. Under this therapy hemoglobin normalized, thrombocytes almost doubled and arthralgia and bowel movement improved.

Taken together, this case reports the successful treatment of small intestinal bleeding with TIPS in a CD patient with azathioprine-induced NRH. Treatment with infliximab induced and maintained remission and seems to be well tolerated in this situation.

\section{Statement of Ethics}

This case report does not require approval by a local ethics committee. Informed consent was obtained from the patient before publishing this case.

\section{Disclosure Statement}

All authors have no conflict of interest to disclosure.

\section{References}

1 Dignass AU, Gasche C, Bettenworth D, Birgegard G, Danese S, Gisbert JP, Gomollon F, Iqbal T, Katsanos K, Koutroubakis I, Magro F, Savoye G, Stein J, Vavricka S; European Crohn's and Colitis Organisation (ECCO): European consensus on the diagnosis and management of iron deficiency and anaemia in inflammatory bowel diseases. J Crohns Colitis 2015;9:211-222.

-2 Vernier-Massouille G, Cosnes J, Lemann M, Marteau P, Reinisch W, Laharie D, Cadiot G, Bouhnik Y, De Vos M, Boureille A, Duclos B, Seksik P, Mary JY, Colombel JF: Nodular regenerative hyperplasia in patients with inflammatory bowel disease treated with azathioprine. Gut 2007;56:1404-1409.

-3 Seksik P, Mary JY, Beaugerie L, Lemann M, Colombel JF, Vernier-Massouille G, Cosnes J: Incidence of nodular regenerative hyperplasia in inflammatory bowel disease patients treated with azathioprine. Inflamm Bowel Dis 2011;17:565-572.

4 Arvanitaki M, Adler M: Nodular regenerative hyperplasia of the liver. A review of 14 cases. Hepatogastroenterology 2001;48:1425-1429.

5 Goel A, Elias JE, Eapen CE, Ramakrishna B, Elias E: Idiopathic non-cirrhotic intrahepatic portal hypertension (NCIPH) - newer insights into pathogenesis and emerging newer treatment options. J Clin Exp Hepatol 2014;4:247-256. 
6 Siramolpiwat S, Seijo S, Miquel R, Berzigotti A, Garcia-Criado A, Darnell A, Turon F, Hernandez-Gea V, Bosch J, Garcia-Pagan JC: Idiopathic portal hypertension: natural history and long-term outcome. Hepatology 2014;59:2276-2285.

7 Musumba CO: Review article: The association between nodular regenerative hyperplasia, inflammatory bowel disease and thiopurine therapy. Aliment Pharmacol Ther 2013;38:1025-1037.

8 Dubinsky MC, Feldman EJ, Abreu MT, Targan SR, Vasiliauskas EA: Thioguanine: a potential alternate thiopurine for IBD patients allergic to 6-mercaptopurine or azathioprine. Am J Gastroenterol 2003;98:1058-1063.

-9 Dubinsky MC, Vasiliauskas EA, Singh H, Abreu MT, Papadakis KA, Tran T, Martin P, Vierling JM, Geller SA, Targan SR, Poordad FF: 6-thioguanine can cause serious liver injury in inflammatory bowel disease patients. Gastroenterology 2003;125:298-303.

10 Grainge MJ, West J, Card TR: Venous thromboembolism during active disease and remission in inflammatory bowel disease: a cohort study. Lancet 2010;375:657-663.

11 Kochhar G, Navaneethan U, Parungao JM, Hartman J, Gupta R, Lopez R, McCullough AJ, Kapoor B, Shen B: Impact of transjugular intrahepatic portosystemic shunt on post-colectomy complications in patients with ulcerative colitis and primary sclerosing cholangitis. Gastroenterol Rep (Oxf) 2015;3:228-233.

12 Wong RC, Berg CL: Portal hypertensive stomapathy: a newly described entity and its successful treatment by placement of a transjugular intrahepatic portosystemic shunt. Am J Gastroenterol 1997;92:1056-1057.

13 Islam KA, Morris-Stiff G: Bleeding stomal varices: a marker of chronic liver disease. BMJ Case Rep 2009;2009:bcr02.2009.1568.

-14 Bollen L, Vande Casteele N, Peeters M, Bessonov K, Van Steen K, Rutgeerts P, Ferrante M, Hoylaerts MF, Vermeire S, Gils A: Short-term effect of infliximab is reflected in the clot lysis profile of patients with inflammatory bowel disease: a prospective study. Inflamm Bowel Dis 2015;21:570-578. 


\section{Case Reports in Gastroenterology}
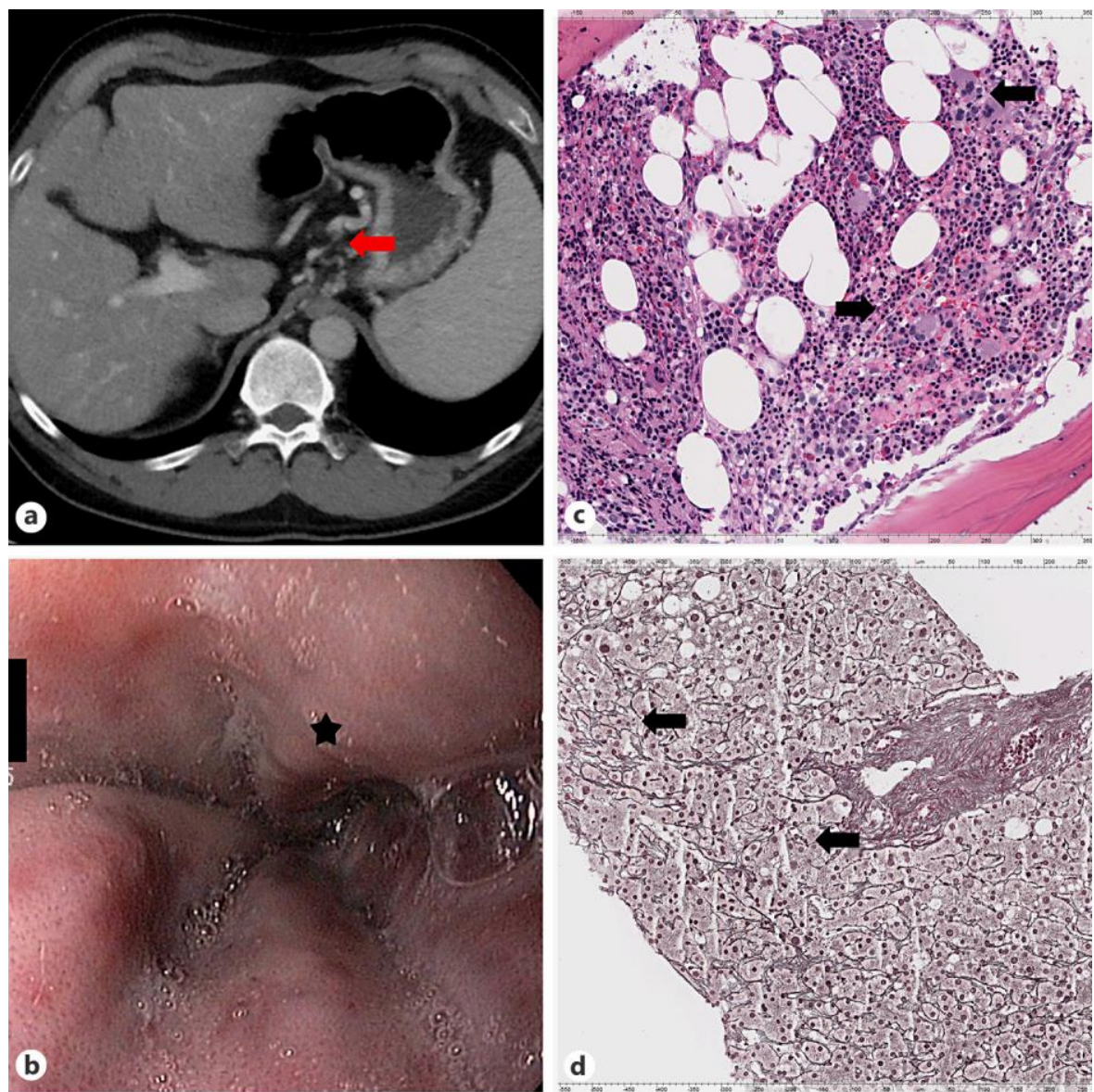

Fig. 1. Azathioprine induced NRH in a patient with CD. a CT scan with portosystemic shunts (arrow). b Endoscopic image of the esophagus with esophageal varices (asterisk) c Bone marrow aspirate with increased megakaryopoiesis (arrows; scale in micrometers on the top and bottom of the image). d Reticulin stain of the liver showing atrophic and hypertrophic hepatocyte cords (arrows) as sign of NRH (scale in micrometers the top and bottom of the image). 


\section{Case Reports in Gastroenterology}

\begin{tabular}{l|l}
\hline Case Rep Gastroenterol 2016;10:589-595 \\
\hline DOI: 10.1159/000450541 & $\begin{array}{l}\text { C 2016 The Author(s). Published by S. Karger AG, Basel } \\
\text { www.karger.com/crg }\end{array}$ \\
\hline
\end{tabular}

Heimgartner et al.: Successful Treatment of Small Intestinal Bleeding in a Crohn's Patient with Noncirrhotic Portal Hypertension by TIPS and Infliximab Treatment
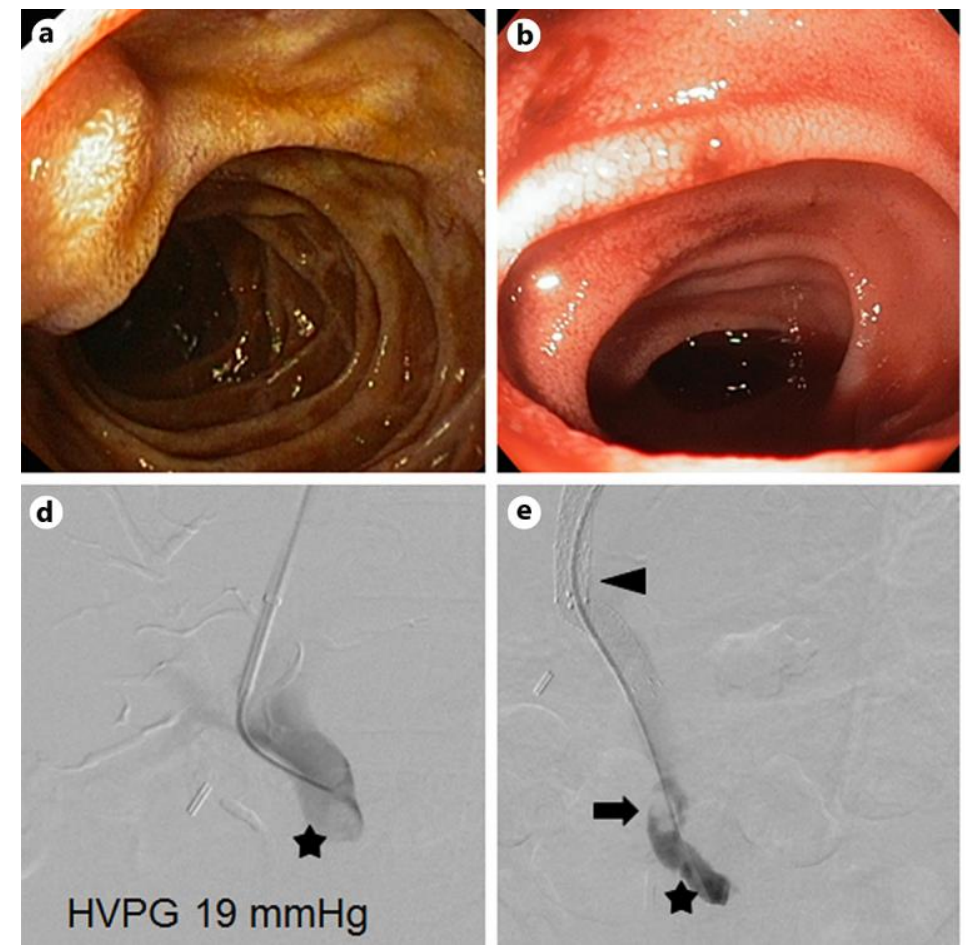
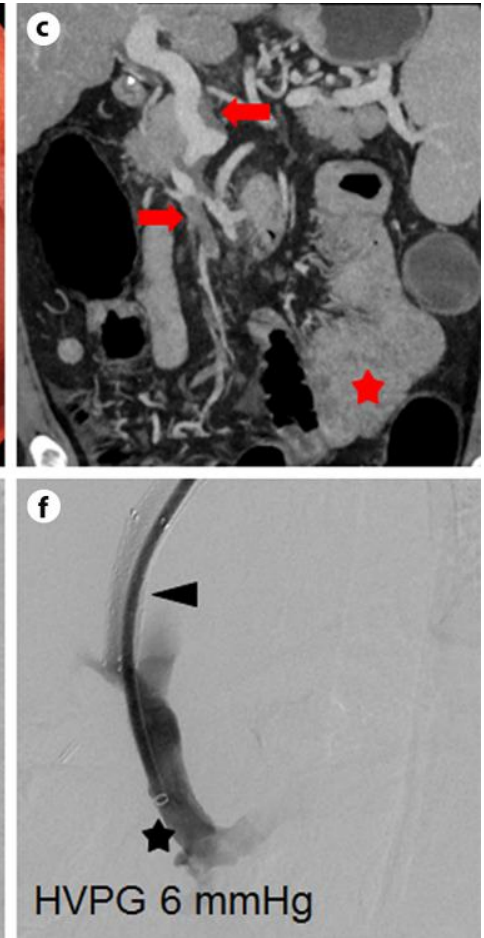

Fig. 2. Admission to the emergency unit with a circulation-relevant intestinal bleeding. a Image of the duodenum during emergency esophagogastroduodenoscopy showing no blood. $\mathbf{b}$ Image of the terminal ileum with fresh blood. c CT scan at admission with partial thrombosis of the superior mesenterial and portal veins (arrows) and a thickened proximal jejunal bowel wall (asterisk). $\mathbf{d}-\mathbf{f}$ TIPS placement and thrombus aspiration. Portosystemic pressure gradient between the right atrium und and the portal vein was lowered from 19 to $6 \mathrm{~mm} \mathrm{Hg}$ after TIPS placement (portal vein: asterisk; TIPS: arrow; thrombus in the portal vein: arrowhead). HVPG = Hepatic venous pressure gradient.

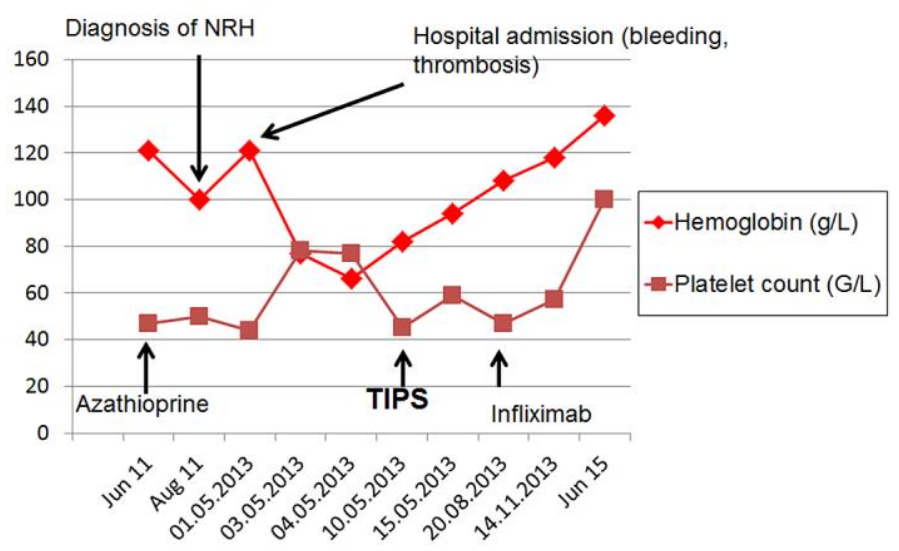

Fig. 3. Thrombocyte and hemoglobin levels. 